Reviews in Digital Humanities • Vol. 2, No. 10

\title{
Review: Connections in Sound
}

\author{
Michael J. Kramer ${ }^{1}$
}

${ }^{1}$ SUNY Brockport

Published on: Oct 11, 2021

DOI: $10.21428 / 3 e 88 f 64 f .30 a b d 624$

License: Creative Commons Attribution 4.0 International License (CC-BY 4.0) 


\section{Project}

Connections in Sound

\section{Project Director}

Patrick Egan, University College Cork

\section{Project URL}

https://rootseire.github.io/LC-ITM/

\section{Project Reviewer}

Michael J. Kramer, SUNY Brockport

\section{Project Overview}

\section{Patrick Egan}

The American Folklife Center at the Library of Congress (LC) houses at least 37 audio collections that are identified as holding items of Irish traditional music. These collections are the result of a wide variety of collecting practices carried out by recordists and fieldworkers from across North America in the 20th century, stretching back to the first wax cylinder recordings from the early 1900s.

In January 2019, a digital pilot entitled Connections in Sound focused on experimenting with these audio collections. The principal aim was to investigate whether fieldwork audio and its attendant metadata could be linked between collections at the LC and across the Internet using proof-of-concept Uniform Resource Identifiers (URIs). Through an iterative approach, the team hypothesized that this activity would lead to valuable technical and humanistic insights about the status and possibilities for Irish traditional music as linked data.

The audience for this type of project includes archivists, scholars of ethnomusicology and digital humanities, and performers of Irish traditional music. To complement the project, the team conducted a survey of the interactions of Irish traditional musicians with digital audio in North America, generating over 524 individual responses. The team is now examining survey results alongside several qualitative interviews with musicians, singers, and dancers from across the continent.

The project is led by Patrick Egan, who was supported by Fulbright and Kluge Center scholarships, but it also involved LC digital expert Matt Miller, the LC Labs team, 
reference librarian Dr. Todd Harvey, and research assistants Emily Kim and Cole Plows. The team collated material from 17 of these collections within a CSV (comma separated values) file using material such as field trip, concert and interview notes, and transcriptions. They also detailed this data set with commentary relating to their decisions about adding item descriptions. Iterative design allowed the data set descriptions to be expanded, resulting in a rich data set of over 2500 records and a detailed overview.

During the development of datasets, three visualizations were developed using D3.js JavaScript library to generate snapshots of the project findings over time. One visualization illustrated each audio collection' s contents using Tableau. In another, a Sankey diagram was generated in D3.js to relay the complexities of the types of musical pieces compared to the physical access to them. A further visualization mapped historical

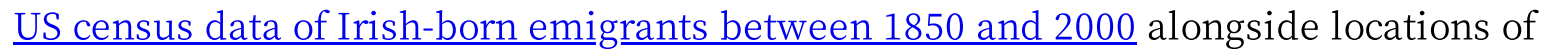
collections.

This metadata was later re-structured to reconcile musical pieces with identifiers from the website, www.irishtune.info. In collaboration with Matt Miller, the team used the Python programming language to create proof of concept linked data triples for each item, connecting to others on the Internet with a recently developed ontology entitled LITMUS (Linked Irish Traditional Music) from the Irish Traditional Music Archive. Linking fieldwork metadata to LC authority files and across the Internet raised humanistic insights and digital issues such as the possible impact of using fieldwork materials with digital infrastructure for Irish traditional music. Software outputs and documentation are openly released via Github.

\section{Project Review}

\section{Michael J. Kramer}

While the study of text and image often drowns out sound and music in digital humanities, the Connections in Sound project, initiated by Patrick Egan during his time as the Library of Congress Kluge Center Scholar in Digital Studies, proves an exception. Egan turns to the rich holdings of traditional Irish music across multiple collections housed at the Library of Congress's American Folklife Center. The goal of his project is to investigate patterns of collecting and accessing traditional Irish music in North America. Egan is curious how the Internet is altering these practices and whether digital circulation can aid processes of musical transmission and performance in positive ways. 
Egan tracks the shifts of field recordings from older media forms of preservation like wax cylinder to compact disc to digital file formats in order to consider the long links between oral tradition and contemporary digital access to musical repositories. Working with librarians, archivists, and digital specialists at the Library of Congress, his project brings together information on over 2,500 individual recordings across 37 collections. A data set of metadata begins to organize the material for exploration and analysis.

Egan's project is in its earliest stages, but the sheer amount of preparatory work completed thus far serves as a reminder of the extensive labor that supports any digital humanities endeavor. There is still much to investigate, including the 526 responses by contemporary musicians, dancers, singers and enthusiasts in North America who Egan surveyed to ask whether "digital access to audio might be transforming engagement among the wider Irish traditional music community?"

For now, one of the most intriguing aspects of Egan's initial efforts are his visualizations of the field recordings found at the Library of Congress using D3.js and the Tableau visualization software. The visualizations propose relationships between repertoire (jigs, reels, hornpipes, songs, etc.) and multiple field recording projects as well as with various modes of technological preservation. There are the typical "hairball" issues with the visualization-what are we to make of all these lines exactly? Yet, potential questions emerge: What are the flows of song style as they differ among collectors, regions, and time periods? Did certain kinds of repertoire predominate in some settings, but not in others? What did it mean, as mapped biographical data suggests in another visualization, for performers to have been born in Ireland or not in terms of the musical repertoire captured in the archive?

Egan's project reminds us that as digital technologies alter modes of access to sound recording repositories, musical traditions themselves are likely to change. They will be loosened from remote corners of the archive and placed more dynamically at play in the contemporary world. Oral tradition and digital transmission, as Miles Foley pointed out in Oral Tradition and the Internet: Pathways of the Mind (University of Illinois Press, 2012), a book Egan looks to for inspiration, potentially have more in common than prior modes of mediated preservation that "freeze" sonic performances to cylinder, record, tape, or CD. The fluidity shared by orality and digitality demands intensification of carework and consideration, attention and analysis. Egan's efforts will surely assist in our capacity to better understand the ways in which the Internet is shifting traditional sounds into new embodiments of Irish musical performance. As old recordings and new 
musicians increasingly come into contact online, one hopes to be hearing more from Patrick Egan and his ongoing investigations of these connections in sound. 